\author{
И.Б. Ершова, Ю.В. Глушко, В.А. Рещиков, И.А. Лохматова, О.В. Петренко
}

ГУ ЛНР «Луганский государственный медицинский университет имени Святителя Луки», Луганск

\title{
ОСОБЕННОСТИ НАРУШЕНИЙ СЕРДЕЧНОЙ ДЕЯТЕЛЬНОСТИ У ДЕТЕЙ ШКОЛЬНОГО ВОЗРАСТА, ПЕРЕНЕСШИХ СТРЕСС ВОЕННЫХ ДЕЙСТВИЙ
}

Вступление. Одной из важных задач современного общества является сохранение и укрепление здоровья детского населения молодых республик, испытавшее стресс военных действий.

На фоне дисстрессовых расстройств [4], к которым относится и посттравматическое стрессовое расстройство (ПТСР), в большинстве случаев наблюдаются отклонения в работе сердечнососудистой системы. Патология со стороны сердечно-сосудистой системы, как правило, сопровождается ухудшением церебральной гемодинамики, что в свою очередь приводит к нарушению мозговой деятельности, дальнейшему вегетативному дисбалансу, усугублению дисстрессовых расстройств [1]. В связи с этим исследование особенностей состояния сердечнососудистой системы у детей, перенесших стресс военных действий, в том числе с ПТСР, остается задачей сложной и до сих пор не решенной. И если сразу после снижения активности боевых действий главное внимание уделялось ПТСР как основному инвалидизирующему фактору, то впоследствии у детей все больше начинали проявляться нарушения со стороны сердечнососудистой системы.

В современной литературе информация о функциональном состоянии сердечнососудистой системы у детей, перенесших стресс военных действий, отражена в единичных работах $[2,3,5]$. В этой связи для выявления характера нарушений сердечной деятельности приобретает значение комплексное обследование детей, оказавшихся в эпицентре военного конфликта, с определением биоэлектрической активности сердца, мозга, а также их адаптационных возможностей.

Анализ литературы показывает, что, несмотря на достижения современной медицины в вопросах сочетанного течения и восстановления детей с нарушениями сердечно-сосудистой и вегетативной нервной систем [1], многие аспекты данной проблемы далеки от решения.
Таким образом, изучение особенностей нарушений сердечной деятельности у детей, испытавших стресс военных действий, является актуальным и перспективным.

В связи с этим целью нашего исследования стал комплексный анализ клиникофункциональных особенностей сердечнососудистой системы, вегетативного гомеостаза и индивидуально-типологических свойств личности детей, оказавшихся в условиях локального военного конфликта.

\section{МАТЕРИАЛ И МЕТОДЫ}

Было проведено углубленное комплексное клинико-инструментальное исследование состояния здоровья и сердечно-сосудистой системы 194 детей в возрасте 7 - 16 лет. Основную группу составили 113 детей (53 девочки и 60 мальчиков), находившихся в регионе во время боевых действий, контрольную группу - 81 ребенок (36 девочек и 45 мальчиков), которые на момент активных боевых действий выезжали за пределы региона.

В соответствии с задачами исследования всем детям проводилось общеклиническое обследование (изучение анамнеза, преморбидного фона, жалоб и симптомов сопутствующих соматических заболеваний).

Для изучения индивидуально-типологических свойств личности проводилось психологическое обследование детей с помощью методик Дембо-Рубинштейна (С.Л. Рубинштейн, 2000), Айзенка (Г. Ю. Айзенк, 1992), Леонгарда-Шмишека (К. Леонгард, 1989). Исследование невербального интеллекта и возможности к абстрактно-логическому мышлению проводилось с помощью теста Дж. Равена (В. И. Белопольский, 1998) [5].

( ) И.Б. Ершова, Ю.В. Глушко, В.А. Рещиков,
И.А. Лохматова, О.В. Петренко, 2020

(C) Университетская Клиника, 2020 
Физическое развитие изучалось по антропометрическим показателям: массе тела, длине тела, окружности груди и головы. При оценке физического развития были использованы таблицы центильного распределения основных антропометрических показателей, разработанных для детей региона.

Артериальное давление измерялось в соответствии с рекомендациями ВОЗ (2000).

Регистрация ЭКГ осуществлялась в 12 стандартных отведениях по общепринятой методике с последующим количественным и качественным анализом. Дозированная физическая нагрузка выполнялась на велоэргометре по прерывистой многоступенчатой методике [6].

Морфометрические показатели сердца, параметры центральной гемодинамики определяли с помощью двухмерной ЭхоКГ.

Изучение вегетативного гомеостаза проводилось с помощью метода кардиоинтервалографии (КИГ) в сочетании с клиноортостатической пробой (КОП) по рекомендациям Р. М. Баевского и соавт. (1984). При анализе вегетативного гомеостаза были использованы региональные таблицы центильного распределения показателей КИГ.

Математическая обработка цифрового материала производилась стандартным пакетом программ STATISTICA, ver. 6.0. Для обеспечения единства методологии применяли непараметрические методы. Качественные признаки оценивались по критерию $\chi^{2}$ Пирсона с поправкой Йейтса, для малых выборок - по двустороннему точному критерию Фишера. Результаты исследования качественных признаков в группах сравнения представлены в виде абсолютных (в \%) частот.

\section{РЕЗУЛЬТАТЫ И ОБСУЖДЕНИЕ}

Исследование показало, что нарушения сердечно-сосудистой системы наблюдались у 104 (92,04\%) детей основной группы. Достоверной разницы в показателях между мальчиками и девочками не выявлено.

При клиническом обследовании 52 ребенка (46,02\%), оказавшихся в эпицентре военных действий, жаловались на кардиалгии: 34 (30,09\%) - на сердцебиение, 31 (27,43\%) - на цефалгии, 30 (26,55\%) - на повышенную утомляемость, 29 (25,66\%) - на возбуждение, 26 (23,01\%) - на нарушения сна. У большинства обследованных детей $(68,14 \%)$ имело место сочетание нескольких жалоб.

Более детальный анализ показал, что у 89,38\% детей, проживавших на территории активных боевых действий, регистрировалась патология нервной системы -преимущественно расстройства вегетативной нервной системы и транзиторные тики: невротические, связанные со стрессом, и соматоформные расстройства - у $24,21 \%$ детей (реакция на тяжелый стресс и нарушения адаптации). У 58,41\% детей выявлены хронические очаги инфекции носоглотки хронические тонзиллиты; у 52,21\% - заболевания органов пищеварения (дискинезия желчного пузыря и желчных путей, классифицируемые в МКБ-10 как «другие уточненные болезни желчного пузыря», а также функциональные расстройства кишечника в виде функциональных диарей); у 38,93\% - нарушения костномышечной системы (деформирующие дорсопатии, а именно сколиозы, кифозы и лордозы); у $14,16 \%$ - болезни мочеполовой системы (циститы, острые тубулоинтерстициальные нефриты).

Исследование физического развития (ФР) показало, что у 57 (50,44\%) детей, находящихся в зоне локального конфликта, независимо от пола регистрировалось среднее ФР, у 44 (38,94\%) низкое. Высокое ФР встречалось в 2,4 раза реже у детей, оказавшихся на территории активных боевых действий, по сравнению с детьми, выехавшими из зоны войны $(10,62 \%$ и 25,93\% соответственно), независимо от пола. Дисгармоничное ФР регистрировалось в $45,13 \%$ случаев, а ретардация роста - в 27,43\%. При этом гармоничное ФР достоверно чаще регистрировалось у мальчиков, а дисгармоничное - у девочек, причем достоверно чаще у последних встречалась ретардация роста.

Во всех возрастных группах достоверно реже, чем в контрольной ( $<<0,001)$, регистрировались значения артериального давления (АД) в рамках возрастной нормы. Повышение АД (33,63\%) и его снижение $(38,05 \%)$ преобладали у детей, испытавших стресс военных действий.

Исследование индивидуально-типологических особенностей позволило установить неадекватную самооценку детей, перенесших стресс военных действий в возрасте 11-13 и 14-16 лет, преимущественно с ПТСР, которые считали себя более несчастными, чем их здоровые сверстники. У детей, оказавшихся в зоне локальных военных действий, выявлен повышенный уровень нейротизма $(38,05 \%)$ независимо от возраста, тревожности $(41,59 \%$ - преимущественно у мальчиков) и заторможенности (34,51\% - преимущественно у девочек). Наблюдалось преобладание типов акцентуаций у подростков, что свидетельствовало о соматизации тревоги. Акцентуации клинически проявлялись снижением настроения, определяли состояние внутреннего напряжения и рассматриваются как критерии формирования групп риска по развитию психосоматических заболеваний. 
Сравнительный анализ невербального интеллекта показал, что у детей с ПТСР через 6 месяцев после окончания активных боевых действий и воздействия травмирующих факторов достоверно чаще, чем в контрольной группе детей, встречались такие нарушения интеллектуального развития, как очень слабый $(23,89 \%$ и $4,94 \%$ соответственно) и слабый $(21,24 \%$ и 9,88\%, $\mathrm{p}<0,05)$.

Проведенный нами анализ ЭКГ позволил выявить у детей, находившихся в зоне военного конфликта, нарушения сердечного ритма в виде наджелудочковой тахикардии (34,51\%), блокады правой ножки пучка Гиса $(29,47 \%)$, атриовентрикулярной блокады и блокады левой ножки пучка Гиса (17,70\%), миграции водителя ритма $(9,73 \%)$, эктопических ритмов $(6,19 \%)$, экстрасистолии $(8,85 \%)$; изменения процессов деполяризации предсердий $(51,33 \%)$ и реполяризации желудочков $(64,60 \%)$, удлинение интервала QT (12,39\%).

Группу риска развития синдрома слабости синусового узла составили 18,58\% детей с синусовой брадикардией, перенесших стресс военных действий, 9,73\% - с миграцией водителя ритма и 5,31\% - с эктопическим ритмом.

Проба с физической нагрузкой выявила, что у 58,41\% детей, перенесших стресс военных действий, показатели ЭКГ (амплитуда зубца Р, продолжительность интервалов PQ и QT, положение сегмента ST) не восстанавливались на 5-й минуте отдыха, что свидетельствовало о наличии у них скрытой функциональной недостаточности сердечно-сосудистой системы.

При эхокардиографическом исследовании выявлено, что малые структурные аномалии развития сердца встречались у 76,99\% детей, находившихся в зоне локального военного конфликта, и 34,57\% детей, выехавших из региона ( $<<0,001)$. Выявленный синдром дисплазии соединительной ткани сердца достоверно чаще наблюдался у детей, проживавших на территории военных действий, чем находившихся в мирных условиях (76,11\% и 38,27\% случаев соответственно, $\mathrm{p}<0,001)$.

При анализе показателей КИГ было выявлено, что у детей, проживавших в мирных условиях, достоверно чаще регистрировалась эйтония $(69,14 \%)$ с преобладанием нормальной вегетативной реактивности (66,67\%), а у детей, переживших стресс войны, - симпатикотония (48,67\%) с преобладанием гиперсимпатикотонической вегетативной реактивности $(58,41 \%)$. У подавляющего большинства детей, оказавшихся в зоне активных военных действий, имела место недостаточная вегетативная обеспеченность; у детей, выезжавших за пределы ре- гиона, чаще всего наблюдалась симпатикотоническая реакция КОП (37,04\%), а у детей, проживавших на территории военных действий, асимпатикотоническая (34,51\%).

Определение функционального состояния сердечно-сосудистой системы с учетом индивидуально-типологических свойств личности позволило изучить уровень адаптационных возможностей детей.

Исследование показало, что удовлетворительные адаптационные возможности достоверно чаще имели дети, проживавшие в мирных условиях, чем дети, находившиеся в состоянии стресса военных действий $(64,20 \%$ и 16,81\% соответственно, $\mathrm{p}<0,01)$ ).

Неудовлетворительная адаптация регистрировалась достоверно чаще у детей, проживавших в зоне военного конфликта $(58,41 \%)$, тогда как в группе сравнения - 31,48\% ( $<<0,05)$.

Таким образом, полученные результаты позволили сделать следующие выводы:

1.У подавляющего большинства детей (92,04\%), находившихся в зоне активных боевых действий, регистрировались нарушения на электрокардиограмме, преимущественно в виде наджелудочковой тахикардии, атриовентрикулярной блокады и блокады левой ножки пучка Гиса, а также блокады правой ножки пучка Гиса.

2. Выявленные электрокардиографические характеристики проявлялись на фоне патологии нервной системы, хронических очагов инфекции носоглотки, заболеваний органов пищеварения, нарушений костно-мышечной системы и заболеваний мочеполовой системы.

3. У 38,94\% детей, находившихся в зоне военного конфликта, выявлено низкое физическое развитие и в 2,4 раза реже регистрировалось высокое физическое развитие.

4. У 33,63\%детей, испытавших стресс военных действий, наблюдалось повышенное АД, и у 38,05\% - пониженное.

5. После физической нагрузки у 58,41\% детей, оказавшихся в эпицентре военного конфликта, показатели ЭКГ не восстанавливались на 5-й минуте отдыха, что свидетельствовало о наличии у них скрытой функциональной недостаточности сердечно-сосудистой системы.

6. Для детей, проживающих в зоне военного конфликта, характерен высокий уровень нейротизма на фоне симпатикотонии $(48,67 \%)$ и гиперсимпатикотонической вегетативной реактивности.

7. Перечисленные изменения способствовали высокой частоте $(58,41 \%)$ неудовлетворительной адаптации у детей, проживавших в зоне военных действий. 


\section{И.Б. Ершова, Ю.В. Глушко, В.А. Рещиков, И.А. Лохматова, О.В. Петренко}

ГУ ЛНР «Луганский государственный медицинский университет имени Святителя Луки», Луганск

\section{ОСОБЕННОСТИ НАРУШЕНИЙ СЕРДЕЧНОЙ ДЕЯТЕЛЬНОСТИ У ДЕТЕЙ ШКОЛЬНОГО ВОЗРАСТА, ПЕРЕНЕСШИХ СТРЕСС ВОЕННЫХ ДЕЙСТВИЙ}

Влияние сильнейшего стрессового фактора на состояние здоровья детей, находившихся в эпицентре боевых действий в регионе Донбасса, в настоящее время является весьма актуальным и недостаточно изученным. Целью данного исследования явилась оценка психосоматического состояния здоровья детей 7-16 лет, в том числе деятельности сердечнососудистой системы. Обследовано 113 детей, проживающих в зоне военного конфликта. Проведено общее клиническое исследование состояния здоровья, включая психопатологические тесты и методики, адаптированные согласно возрасту, оценку физического развития (соматометрические и физиометрические данные), электрокардиографию, эхокардиографию и кардиоинтервалографию. В результате проведенного исследования выявлены психоэмоциональные нарушения (у 100\%) и функциональные нарушения сердечно-сосудистой системы у 104 (92,04\%) детей основной группы, с преобладанием жалоб на кардиалгии, сердцебиение, цефалгии, повышенную утомляемость, возбуждение, нарушения сна. Анализ электрокардиограмм выявил нарушения сердечного ритма в виде наджелудочковой тахикардии (34,51\%), блокады правой ножки пучка Гиса $(29,47 \%)$, атриовентрикулярной блокады и блокады левой ножки пучка Гиса $(17,70 \%)$, миграции водителя ритма $(9,73 \%)$, эктопических ритмов $(6,19 \%)$, экстрасистолии $(8,85 \%)$; изменения процессов деполяризации предсердий $(51,33 \%)$ и реполяризации желудочков
(64,60\%); удлинение интервала QT (12,39\%). Зарегистрировано снижение уровня физического развития в основной группе. У детей, длительно находившихся в стрессовой ситуации военного конфликта, значительно чаще встречалась соматическая патология, в частности патология нервной системы $(89,38 \%)$ - расстройства вегетативной нервной системы и транзиторные тики; невротические, связанные со стрессом, и соматоформные расстройства - у $24,21 \%$ детей (реакция на тяжелый стресс и нарушения адаптации). У $58,41 \%$ детей выявлены хронические очаги инфекции носоглотки - хронические тонзиллиты; у 52,21\% - заболевания органов пищеварения (дискинезия желчного пузыря и желчных путей, классифицируемые в МКБ-10 как «другие уточненные болезни желчного пузыря», а также функциональные расстройства кишечника в виде функциональных диарей); у 38,93\% нарушения костно-мышечной системы (деформирующие дорсопатии, а именно сколиозы, кифозы и лордозы); у 14,16\% - болезни мочеполовой системы (циститы, острые тубулоинтерстициальные нефриты).

Вегетативный гомеостаз характеризовался преобладанием симпатикотонического тонуса $(48,67 \%)$ и гиперсимпатикотонической вегетативной реактивности. Длительное нахождение в зоне боевых действий значительно снизило адаптационные возможности детей, что привело к развитию дистресса.

Ключевые слова: дети, стресс, состояние здоровья, сердечно-сосудистая система.

\section{I.B. Ershova, Yu.V. Glushko, V.A.Reshchikov, I. A. Lokhmatova, O. V. Petrenko}

SI LPR «St. Luke Lugansk State Medical University», Lugansk

\section{PECULIARITIES OF CARDIAC DISORDERS IN CHILDREN OF SCHOOL AGE AFTER MILITARY STRESS}

The influence of the strongest stress factor on the health status of children who were at the epicenter of hostilities in the Donbass region is currently very relevant and insufficiently studied. The aim of this study was to assess the psychosomatic health status of children 7-16 years old, including the activity of the cardiovascular system. A total of 113 children living in the military conflict zone were examined. A general clinical study of the state of health was carried out, including: psychopathological tests and methods adapted according to age, assessment of physical development (somatometric and physiometric data), electrocardiography, echocardiography and cardiointervalography. The study revealed psychoemotional disorders (in 100\%) and functional disorders of the cardiovascular system in $104(92,04 \%)$ children of the main group with a predominance of complaints of cardialgia, palpitations, cephalgia, increased fatigue, agitation, sleep disturbances. An analysis of the electrocardiogram revealed cardiac arrhythmias in the form of supraventricular tachycardia (34,51\%), right bundle branch block $(29,47 \%)$, atrioventricular block and left bundle branch block (17,70\%), wandering pacemaker(9,73\%), ectopic rhythms $(6,19 \%)$, extrasystole $(8,85 \%)$; changes in the processes of atrial depolarization $(51,33 \%)$ and ventricular repolarization (64,60\%); prolongation of the QT interval (12,39\%). A decrease in the level of physical development in the main group was recorded. In children who were in a stressful situation of a military conflict for a long time, the incidence of somatic pathology significantly exceeded, in particular, the pathology of the nervous system $(89,38 \%)$ (disorders of the autonomic nervous system and transient tics); neurotic, stress-related and somatoform disorders (in $24,21 \%$ of children) (reaction to severe stress and adaptation disorders); chronic foci of nasopharyngeal infection $(58,41 \%)$ (chronic tonsillitis); diseases of the digestive system $(52,21 \%)$ ( gallbladder dyskinesia and biliary dyskinesia, classified in the ICD - 10 as "other specified diseases of the gallbladder", as well as functional intestinal disorders in the form of functional diarrhea); disorders of the musculoskeletal system $(38,93 \%)$ (deforming dorsopathies, namely scoliosis, kyphosis and lordosis); diseases of the genitourinary system $(14,16 \%)$ (cystitis, acute tubulointerstitial nephritis). Autonomic homeostasis was characterized by a predominance of sympathicotonic tonus $(48,67 \%)$ and hypersympathicotonic vegetative reactivity. Prolonged stay 
in the combat zone significantly reduced the adaptive capabilities of children, which led to the development of distress.
Key words: children, stress, state of health, cardiovascular system.

\section{ЛИТЕРАТУРА}

1. Безруких М., Сонькин В., Фарбер Д. Возрастная физиология: (физиология развития ребенка). Учебное пособие для студентов высших педагогических учебных заведений. M.: Academa; 2013. 416.

2. Глушко Ю.В., Яковенко Ю.О., Беликова У.М. Функциональное состояние сердечно-сосудистой системы у детей младшего школьного возраста с посттравматическим стрессовым расстройством (по данным пробы Руфье). Материалы Всероссийского научного форума с международным участием «Студенческая наука - 2017». Под ред. Багатурия Г. О. СПб.: Издание СПбГПМУ. 2017: 10.

3. Дубовая А.В., Пшеничная Е.В., Бордюгова Е.В., Конов В.Г., Тонких Н.А. Психовегетативный синдром у детей в условиях военного конфликта, пути его коррекции. Университетская клиника. 2015; Т. 11, 2: 64-68.

4. Ершова И.Б., Глушко Ю.В., Копейка И.А. Состояние здоровья младших школьников, испытавших стресс в результате военных действий. Проблемы экологической и медицинской генетики и клинической иммунологии: Материалы Международной научнопрактической конференции «Здоровье людей - высшее благо общества». Луганск, 19 декабря 2017 г., Луганск; 2017: 128-130.

5. Райгородский Д.Я. Практическая психодиагностика. Методики и тесты.М.: Бахрах-М; 2017. 159.

6. Михайлов В.М. Нагрузочное тестирование под контролем ЭКГ: велоэргометрия, тредмилл-тест, степ-тест, ходьба. Иваново: А-Гриф; 2015. 440.

\section{REFERENCES}

1. Bezrukikh M., Son'kin V., Farber D. Vozrastnaya fiziologiya: (fiziologiya razvitiya rebenka). Uchebnoe posobie dlya studentov vysshikh pedagogicheskikh uchebnykh zavedenii. M.: Academa; 2013. 416 (in Russian).

2. Glushko Yu.V., Yakovenko Yu.O., Belikova U.M. Funktsional'noe sostoyanie serdechno-sosudistoi sistemy u detei mladshego shkol'nogo vozrasta s posttravmaticheskim stressovym rasstroistvom (po dannym proby Ruf'e). Materialy Vserossiiskogo nauchnogo foruma s mezhdunarodnym uchastiem «Studencheskaya nauka 2017». Pod red. Bagaturiya G. O. SPb.: Izdanie SPbGPMU. 2017: 10 (in Russian).

3. Dubovaya A.V., Pshenichnaya E.V., Bordyugova E.V., Konov V.G., Tonkikh N.A. Psikhovegetativnyi sindrom u detei v usloviyakh voennogo konflikta, puti ego korrektsii. Universitetskaya klinika. 2015; T. 11, 2: 64-68 (in Russian).

4. Ershova I.B., Glushko Yu.V., Kopeika I.A. Sostoyanie zdorov'ya mladshikh shkol'nikov, ispytavshikh stress v rezul'tate voennykh deistvii. Problemy ekologicheskoi i meditsinskoi genetiki i klinicheskoi immunologii: Materialy Mezhdunarodnoi nauchno-prakticheskoi konferentsii «Zdorov'e lyudei - vysshee blago obshchestva». Lugansk, 19 dekabrya 2017 g., Lugansk; 2017: 128-130 (in Russian). 5. Raigorodskii D.Ya. Prakticheskaya psikhodiagnostika. Metodiki i testy.M.: Bakhrakh-M; 2017. 159 (in Russian).

6. Mikhailov V.M. Nagruzochnoe testirovanie pod kontrolem EKG: veloergometriya, tredmill-test, step-test, khod'ba. Ivanovo: A-Grif; 2015. 440 (in Russian). 